onset of small-pox to have any influence on the discase (see following table) :-

\section{Small-fox in the "Ke-vaccinated."}

190 persons who were stated to have been re-vaccinated were attacked by small-pox. Of these :

(a) 52 were "re-vaccinated" at various periods prior to epidemic, in some cases several years.

In 37 this re-vaccination was stated to have been successful, and 2 of these patients died.

In 15 this re-vaccination did " not take"-1 died.

(b) 30 were " re-vaccinated" between 3 months and 14 days of the attack of small-pox.

$$
\begin{aligned}
& \text { In } 8 \text { the vaccination " took." } \\
& \text { In } 22, " \text { " did not take." }
\end{aligned}
$$

(c) $10 S$ were " re-vaccinated" within I4 days of appearance of small-pox eruption, some of them even in early days of attack.

In 83 vaccine vesicles appeared -4 died.

In 25 the vaccination did" "not take"-1 died.

Where Re-vaccination believed to have been successful.

(a) 37 cases-2 deaths-fatality $5 \% 4$ per cent.

$\begin{array}{lllll}\text { (b) } 8 & 8 & 0 & , & \end{array}$

Where R'e-zaccination known to have been unsuccessful.

(a) 15 cases -2 deaths--fatality 13.3 per cent.

(b) $22, "$ o, , nil.

(c) 25 " I ", ", 40 per cent.

Or of whole number, $4^{.8}$ per cent. ; or if we take whole number (190), irrespective of date or of success, a fatality of 47 per cent.

Ir. Wheeler's statement that the accepted fatality before Jenner's birth was $16^{\circ} 6$ has very little bearing on the question, since the epidemic at Gloucester gave $2 I^{\circ} 9$, and this, including the $42 * 2$ per cent. unvaccinated fatality at all ages, which is less than that between $I$ and 10 years, the period of most fatal small. pox, in the pre-vaccination days. The Gloucester outbreak was undoubtedly unusually virulent; but, surely, equally severe epidemics are on record.

Tile Writer of the Article.

\section{THE SOUTH KENSINGTON SCIENCE BUILDINGS.}

$\mathrm{W}^{\mathrm{E}}$ $\mathrm{E}$ are glad to see that the various important matters connected with the extraordinary proposal to spend some eight hundred thousand pounds in interlacing the Science with the Art .buildings-chemical laboratories with picture galleries - are being considered by a Parliamentary Committee. This is more especially desirable, since, as we have previously pointed out, it is stated that about half the money proposed to be spent is sufficient for present needs.

The Times gives the following account of the meeting of the Select Committee on Friday last, Sir F. S. Powell presiding. Sir John Donnelly, secretary to the department, was further examined. Sir $\mathrm{H}$. Howorth said it would be of great assistance to the Committee if they could get from the officials of the department an expression of their views as to the changes which were desirable or were not desirable in regard to the housing of the Science and Art collections. The witness said that was rather an awkward question; he really did not think it would be proper for him to volunteer any statement whick might conflict with the present proposals of the Treasury and the Board of wVorks. He had already stated that, in his opinion, the Science collections should be on the west side of Exhibition Road and the Art collections on the east side. He believed that that was the proper solution of the South Kensington question, and he had seen no reason in what had taken place since he gave expression to that view to change his opinion. Sir H. Howorth: Mr. Akers
Douglas has stated that, with the removal of the residences and of the secretarial offices to Whitehall, the Government find that they will have at their disposal a much larger space than had been previously contemplated, and that therefore they will be able to put the Science and Art collections on the one side of Exhibition Road. Do you think the space thus provided will be sufficient for the whole of the collections being placed together? The witness: I do not think so, and that was my reason for saying that I saw no ground for changing the opinion I have already expressed on the subject. I contemplate that the museums will increase, and I do not think it would be wise to consolidate the collections on one side of the road. In answer to further questions, Sir John Donnelly said he thought it was most desirable that the Geological Museum in Jermyn Street should be transferred to South Kensington. The library which was now in Jermyn Street would be of great value at South Kensington, and under the present system of division they had to duplicate many of the books. He would undertake to bring this view before the Lord President and the Vice.President of the Council. As to the Art side, the theory that it was better to bave a large series of small rooms in which they could classify their objects rather than a series of very large halls or rooms was absolutely impracticable in their case. He was distinctly in favour of residences being provided for some of the officers-say four-either in the same buildings in which the collections were housed or very close to them. There was, he knew, a morbid fear of fire being caused when the residences were in the actual building, but he did not himself believe that this was a very great source of danger.

\section{PHOTOGRAPHY AND TRAVEL.'}

THE globe-trotter of to-day is almost as notorious for his poor photographs as his ancestor of the Mandeville era was for his traveller's tales. Without instruction in the technical part of his work, and without the geographical training required to teach him what to look for and how to view it, he habitually brings home productions which may be of interest as studies for an impressionist artist, but are of little or no value to the student of nature. Hence it is with particular pleasure that we welcome the republication in a generally acces. sible form of a selection of Mr. Thomson's magnificent photographs made in China. These were taken before the days of dry plates and snap-shots, when it was necessary to prepare and develop the plates on the spot, and to employ a camera of large dimensions not easy tc transport through regions where, to says the least, strangers are not received with overwhelming hospitality.

The photographs are selected so as to give a connected idea of life in China proper in all its aspects, and also to illustrate the natural scenery of many of the provinces and of Formosa. The pictures are so satisfactory from every point of view, that it is no slight to say that from every point of a humbler place when one estimates the value of the. book. The text for the most part is descriptive of travel, and illustrative of the photographs, incidents and anecdotes being introduced for that purpose. It would have been more useful if the exact order of the journeys and their date had been mentioned ; and a map might very well have been added to show the situation of the regions visited.

Three introductory chapters deal with the condition of China now and in the past, and with the Chinaman abroad and at home. Having regard to the somewhat acute interest now being taken in China by the nations 1 "Through China with a Camera" By John Thomson, F.R.G.S. 1 "Through China with a Camera"
With nearly roo illustrations, Pp. xiv +284 . Small 4 to. (Westminster: A. Constable and Co., 1898 .)

No. 1484 , vOL. 57] 
of Europe, the perusal of these chapters should prove useful ; and so should the description of the various great centres of population on the coast, in the Yangtie valley and Pekin.

Not the least interesting of the photographs is that which, by the courtesy of the publishers, we are able to give here. The illustration shows two ancient astronomical instruments of purely Chinese construction, which staud on the walls of Pekin, with instruments dating from the thirteenth century, and others constructed for the Chinese Government by the Jesuit missionaries of the seventcenth century. The circles of comparatively few astronomical observers, that means of communication were slow, and that the importance of recording these objects as precisely as possible had not been recognised.

The present is perhaps an appropriate period to refer to this subject, for it was in 1798, just a century ago, that the first systematic attempt was made (by Brandes at Leipzic, and Benzenberg at Dusseldorf) to determine the heights of meteors. Schröter had in 1795 seen a shooting. star (in his reflecting telescope of 20 feet focus), the height of which he estimated at more than four millions of miles! Brandes and Benzenberg, however, found

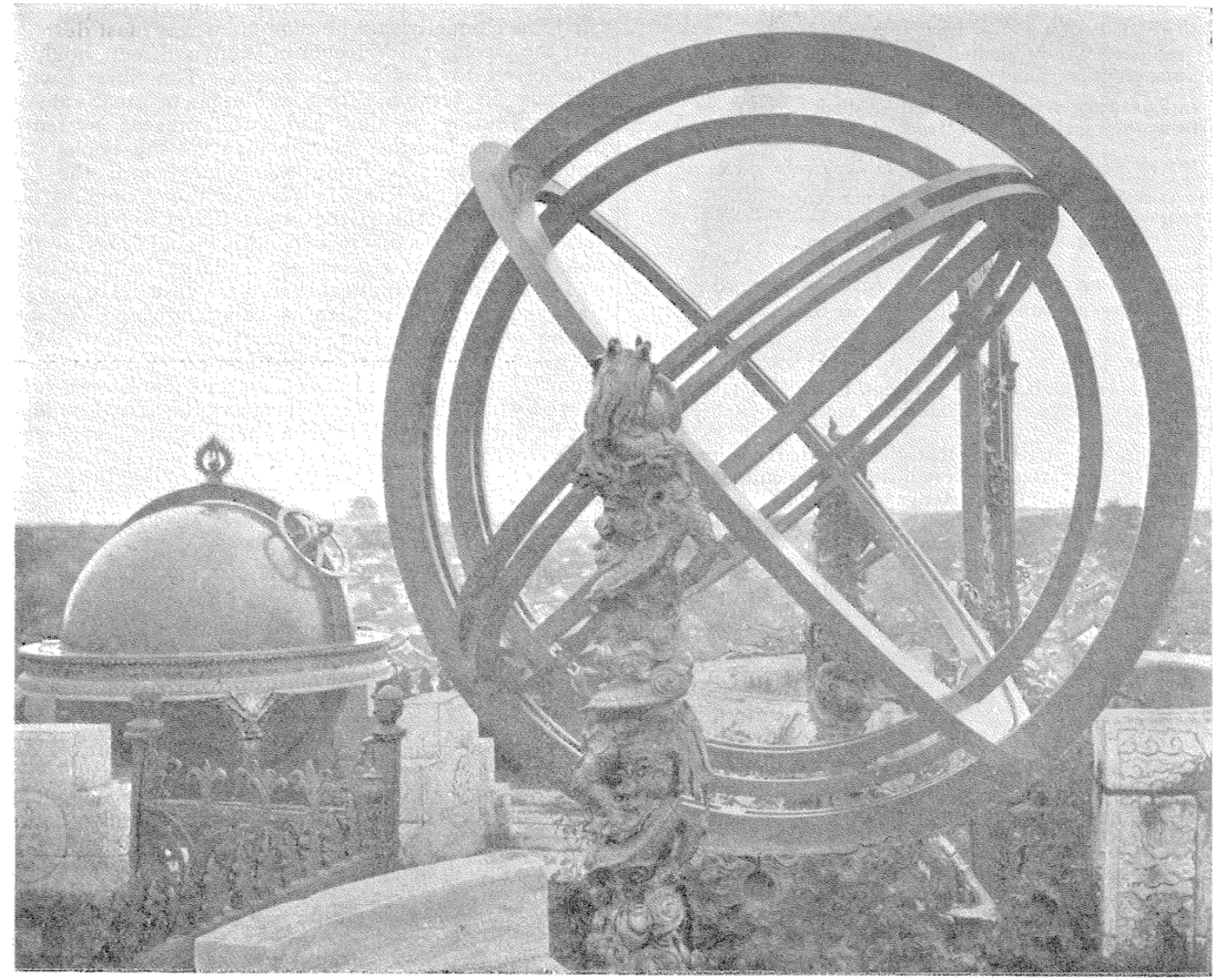

Ancient Chinese Astronomical Instruments.

the instruments of the thirteenth century are divided into $365^{1}$ degrees to correspond to the days of the year, each degree being subdivided into hundredths, but the later instruments have their circles divided into 360 degrees.

\section{THE HEIGHTS OF METEORS.}

$\mathrm{I} T$ is perhaps surprising that the heights of meteors, and especially of that class known as fireballs, were not determined with any accuracy until the near approach of the present century. It is true that a few individual attempts were made in this direction but, considering the large number of brilliant meteors which appear every year, it is curious that some systematic attempts were not made at a much earlier date in this direction. It must, however, be remembered that many years ago there were from 22 meteors which they mutually observed in 1798 , heights varying between 6 and 140 miles. Brandes in. stituted some further observations in 1823 , and of 62 meteors available for calculation 55 were found to have heights between 30 and 70 miles. On August 10, 1838 , M. Wartmann, at Geneva, followed up Brandes's inquiries, and derived the average height of the meteors seen on that occasion as 550 miles, and their velocity 240 miles a second. These values, compared with modern observations, were far less accurate than Brandes's earlier ones.

It is not proposed in this paper to deal fully with the average heights of meteors, for that has been discussed by several authorities. The values are about 76 and 51 miles respectively for the mean elevations at appearance and disappearance. In the case of fireballs, however, they penetrate much deeper into our atmosphere than

No. 148 , vOL. 57$]$ 